ISSN 0103-7013

Psicol. Argum., Curitiba, v. 29, n. 64, p. 121-132 jan./mar. 2011

Licenciado sob uma Licença Creative Commons

\title{
Um movimento em cânone: Tecendo uma metáfora entre a constituição do sujeito e o Canon em ré de Pachelbel
}

\author{
A canon movement: Framing a metaphor between the \\ constituition of the subject and the Pachelbel's Canon in D
}

\author{
Patrícia Wazlawick $^{[\mathrm{a}]}$, Kátia Maheirie ${ }^{[\mathrm{b}]}$, Glauber Benetti Carvalho ${ }^{[\mathrm{c}]}$
}

[a] Musicoterapeuta, Doutora em Psicologia pela Universidade Federal de Santa Catarina (UFSC), professora da Faculdade Antonio Meneghetti (AMF), e-mail: patriciawazla@gmail.com

[b] Psicóloga, Doutora em Psicologia Social pela Pontifícia Universidade Católica de São Paulo (PUC-SP), professora do Departamento e da Pós-Graduação, Mestrado e Doutorado, em Psicologia da Universidade Federal de Santa Catarina (UFSC), Florianópolis, SC - Brasil.

[c] Músico violonista, integrante do Comtrasteduo (duo de violões), compositor, educador musical e musicoterapeuta, Curitiba, PR - Brasil.

\section{Resumo}

O objetivo deste trabalho teórico é discutir o processo de constituição do sujeito, considerando a perspectiva sócio-histórica da psicologia, a partir de uma discussão com as objetivações artístico-estéticocriadoras, mais especificamente a música. Para tanto, foi estudada e analisada a estrutura musical da peça Canon em ré, de autoria de Johann Pachelbel, o qual é situado historicamente, assim como sua produção musical, como metáfora para o processo de constituição do sujeito. Falar da constituição do sujeito é falar do movimento dialético que existe entre objetividade e subjetividade. Pela recíproca transformação entre essas dimensões, ao longo da história, o sujeito vai se constituindo como uma síntese aberta e inacabada em meio ao contexto sócio-histórico-cultural, sendo simultaneamente produto e produtor, constituído e constituinte desse contexto. Dessa forma, pode-se apontar para o movimento histórico de constituição do sujeito em sua processualidade, um movimento aberto e inacabado, em que as "vozes" presentes vão tecendo uma síntese que se faz, por sua vez, também aberta e inacabada, compondo sujeitos em um constante (re)criar a/da própria vida.

Palavras-chave: Constituição do sujeito. Psicologia sócio-histórica. Música. Canon em ré. Pachelbel. 


\begin{abstract}
The objective of this theoretic work is discuss a process of constitution of the subject, considering a perspective of the social-historic psychology, from of one discussion with the artistic-esthetic-creators objectify, more specify the music. For that, was studied and analyzed the musicals structure of the play Canon in D of Johann Pachelbel, who is historically, situate, as his musical composition, as a metaphor for the process of constitution of the subject. When talking about the constitution of the subject we are talking about the movement in dialect that exists between objective and subjective. For the reciprocate transformation between theses dimensions throughout history, the subject continues to happen with a open synthesis and never ending inside the social-historic-cultural context, being simultaneously the product and the producer, constituted and constituent in this context. This form, can show for the historic move of subject constitution, in his process, one open and unfinished movement, where the present "voices" will be building one synthesis, that makes, also open and unfinished, composing the subjects, in one constant (re)create the/of proper life.
\end{abstract}

Keywords: Constitution of the subject. Social-historic psychology. Music. Canon in D. Pachelbel.

\section{Introdução}

\section{Um baixo contínuo...}

"O mundo é transformação. Tudo muda, a própria história muda. Os homens estão constantemente inventando novos instrumentos de trabalho, mudam a ordem social, mudam a si mesmos. O velho é sempre substituído pelo novo, e cada coisa, ao nascer, já tem em si o germe da sua destruição. Portanto, não há 'coisas acabadas', mas um complexo deprocessos onde tudo sóéestável na aparência".

(Aranha \& Martins, 1993, p. 88)

Iniciamos com uma obra musical, uma composição feita por um compositor há mais de trezentos anos, que, na discussão com o musicoterapeuta norueguês Dr. Even Ruud (2003), foi definida, por ele, como uma metáfora para a identidade, ou para o processo de construção de identidade, ${ }^{1}$ e que nestes escritos será (re)pensada, então, como uma metáfora para o processo de constituição do sujeito. Pois, tal como diz Lúcia Santaella (1983, p. 139), "toda definição acabada é uma espécie de morte, porque, sendo fechada, mata justo a inquietação e a curiosidade que nos impulsionam para as coisas que, vivas, palpitam e pulsam".

O compositor da música da qual se faz agora uma metáfora para o processo de constituição do sujeito é Johann Pachelbel. Nasceu em Nuremberg, na Alemanha, no ano de 1653 e faleceu em 1706. ${ }^{2}$ Pachelbel foi compositor e organista. Seus primeiros estudos formais em música foram com dois músicos locais, a saber, Heinrich Schwemmer e G. C. Wecker. Conta a história que, em 1669, Johann Pachelbel ingressou na Universidade de Altdorf

1 Compreendemos, tal como visto em Maheirie (2002), que o conceito de identidade aponta uma multiplicidade de significados, sendo permeado por elementos polêmicos e contraditórios. Em nível de esclarecimento: não iremos nos deter na discussão do conceito de identidade nesses aspectos. Para tanto, trataremos de abordar a temática e a compreensão da "constituição do sujeito", com base na abordagem sócio-histórica da psicologia.

2 Pachelbel fez parte do período do Primeiro Barroco na música ocidental, aproximadamente entre 1620 e 1700 . Foi um período ou estilo da música europeia que se caracterizou por ser extravagante, ornamentado, elegante, irregular. Os reis e a igreja empregavam compositores, que eram tratados como empregados e compunham temas baseados na religião ou temas que a nobreza solicitava. Frequentemente eram avisados para compor em espaços de tempo muito curtos. No período barroco, deu-se o início dos concertos instrumentais. O cravo, instrumento musical de teclado, foi muito popular nesse período e muitos compositores foram cravistas excepcionais (Andrade, 2005). A música, caracterizada por elaborada ornamentação, incluía a forte presença do baixo contínuo e tinha ênfase nos contrastes (de textura, andamento, volume sonoro) (Sadie, 1994). Alguns dos principais músicos desse período foram: Primeiro Barroco (1620-1700): Frescobaldi, Lully, Purcell, Charpentier, Corelli, Pachelbel, Monteverdi; Segundo Barroco (1700-1750): Johann Sebastian Bach, Antonio Vivaldi, Georg Philipp Telemann, Handel, Albinoni, Rameau, Couperin. O termo barroco é uma palavra portuguesa que significa "pérola de formato irregular", no sentido de sugerir “estranheza, irregularidade, extravagância" (Sadie, 1994). 
(Viena), onde, tendo 18 anos de idade, foi organista da Lorenzkirche, mas teve de abandonar o cargo menos de um ano depois, por causa da falta de dinheiro para continuar os estudos. No ano seguinte, 1670, matriculou-se no Gymnasium Poeticum de Regensburg, onde pode prosseguir seus estudos de música com Kaspar Prentz. Foi também organista da Catedral de Santo Estevão, em Viena, permanecendo por cinco anos. Trabalhou e morou também em Stuttgart e Eisenach. No entanto, foi na cidade de Erfurt que Pachelbel permaneceu por doze anos, como organista, compositor e professor de música. Nessa época lecionou música para Johann Christoph Bach, o irmão mais velho de Johann Sebastian Bach (Sadie, 1994).

Enquanto trabalhou em Erfurt, Johann Pachelbel alcançou um sucesso notável como organista, compositor e professor. Casou-se duas vezes - a esposa e os filhos do primeiro casamento faleceram. Deixou tal cidade em 1690 e após breves períodos em Stuttgarte Gotha retornou à Nuremberg. Ali, em 1695, foi indicado para organista da Saint Sebalduskirche, permanecendo até a sua morte (Sadie, 1994, p. 691).

Um de seus alunos foi Johann Christoph Bach, quem, por sua vez, deu ao seu irmão mais novo, Johann Sebastian Bach, suas primeiras lições de teclado. Todos os seus trabalhos são em estilo contrapontístico simples, predecessor do estilo de Johann Sebastian Bach, particularmente em sua técnica de variação coral. Suas composições para órgão mostram um conhecimento das formas italianas derivadas de Frescobaldi, através de J. J. Froberger [...]. De importância especial são seus prelúdios corais, que contribuíram muito para estabelecer as melodias corais do protestantismo do norte da Alemanha, na atmosfera lírica do sul, católico. Carl Philipp Emanuel referia-se a Pachelbel como um compositor cujas obras seu pai, Johann Sebastian Bach, tinha admirado (Franco, 2005).
De acordo com Franco (2005), Pachelbel foi um organista tão genial na improvisação e na técnica do contraponto quanto o italiano Girolamo Frescobaldi (1583-1643). ${ }^{3}$ Conhecido também como um grande solista de órgão e cravo, tornou-se o músico mais importante da escola de órgão no sul da Alemanha, antes de Johann Sebastian Bach. Seu trabalho musical, evidenciando sua música para órgão, inclui, daquilo que foi mantido e conservado até hoje - apesar da maioria de sua produção estar ainda sob a forma manuscrita -, cerca de 70 corais, 95 fugas para o Magnificat, e obras não litúrgicas como tocatas, prelúdios, chaconas, ${ }^{4}$ corais, suítes, motetos, ${ }^{5}$ fugas e fantasias. Tinha preferência por um estilo simples, preocupado com o equilíbrio e a clareza musical, tendo encontrado sua expressão mais plena na música vocal, que inclui duas missas e algumas importantes partituras para vésperas, bem como árias e concertos sacros. Entre suas contribuições para a música de câmara inclui-se o Cânone (Canon em ré), que se tornou sua obra mais conhecida (Sadie, 1994).

\section{Desenvolvimento}

"O que é, exatamente por ser tal como é, não vai ficar tal como está".

(Brecht, citado por Aranha \& Martins, 1993, p. 88)

\section{A música}

Cânone em ré maioré o nome da música que se torna agora figurante da metáfora que estamos tecendo sobre o processo de constituição do sujeito. Diz-se que "se torna agora", visto que é uma significação que a mesma assume, dada ou conferida a ela por algumas pessoas que, em base a uma nova forma de escutá-la e olhá-la, constroem, junto de seus sentidos, essa significação, nesse momento histórico, de acordo com algo vivido, pensado e sentido em relação a essa composição. ${ }^{6}$ Certamente Pachelbel nem sequer se

3 Pachelbel soube combinar o tecnicismo dos compositores alemães com o virtuosismo dos mestres italianos, criando um estilo que foi atingir seu apogeu com Johann Sebastian Bach (Franco, 2005).

4 Peça instrumental, em compasso ternário ou quaternário, de andamento lento, construída sobre um baixo contínuo de quatro a oito compassos, seguido de variações (Dicionário Aurélio da Língua Portuguesa, versão digital).

5 Composição polifônica, de caráter religioso ou profano, a várias vozes (a capela ou com acompanhamento instrumental), e cada uma com ritmo e texto próprios (Candé, 1964, p. 88).

6 Discussão realizada durante o curso do musicoterapeuta norueguês Dr. Even Ruud (da Universidade de Oslo, Noruega), intitulado Música e Identidade: Musicoterapia, Musicologia e Cultura, realizado de 2 a 5 de novembro de 2003, no Conservatório Brasileiro de Música (CBM/CEU), na cidade do Rio de Janeiro, RJ, Brasil, no qual a autora musicoterapeuta (deste) esteve presente, junto a um público em que se encontravam vários musicoterapeutas profissionais e estudantes de musicoterapia brasileiros. 
preocupou com essa analogia. No entanto, é uma possibilidade ao nos apropriarmos da música e fazermos uma leitura musical estrutural conferindo a ela essa significação.

A forma musical "cânone" é uma forma de composição muito difundida pelos compositores do século XVI e cujo tema, iniciado por uma vOz - o antecedente-, é continuamente imitado por outra(s) voz(es) - o(s) consequente(s) -, à distância de um ou mais compassos, até o fim. O cânone pode ser: em uníssono, quando as vozes repetem exatamente as mesmas notas; à oitava, quando os consequentes são transpostos à oitava; e circular ou rota, quando as imitações percorrem todos os tons (Ferreira, 1977).

De acordo com Horta (1985, p. 64), a forma musical chamada de cânone constitui uma

técnica ou peça em que uma melodia imita exatamente uma outra (normalmente à pequena distância), como se a estivesse perseguindo, mas sem nunca alcançá-la. A imitação pode ser a duas, três, ou mais voz, em uníssono ou em intervalos diferentes. Essa forma originou-se no século XIII.

No Dicionário Grove de Música encontra-se que o cânone é:

A forma mais rigorosa de imitação contrapontística em que a polifonia é derivada de uma única linha melódica, através de imitação estrita em intervalos fixos ou (menos freqüente) variáveis de altura e de tempo. O termo vem sendo usado desde o século XVI para designar obras compostas no gênero. Entre os tipos específicos incluem-se rota, round, cânone em retrógrado e cânone em espelho. No século XIV a escrita canônica floresceu em gênero como a caccia e o rondeluz, atingindo seu auge com as obras de Machaut. Os mestres flamengos do século XV empregaram-na com crescente complexidade e, embora sua importância como forma criativa tenha declinado no século XVI, começou a desenvolver-se como tema de estudo [...]. As técnicas canônicas tiveram pouco espaço na música da era sinfônica ou no período romântico, mas as escolas neoclássicas e serial do século XX restituíram-lhe proeminência (Sadie, 1994, p. 163).
Para uma breve definição, visto que os termos musicais serão importantes na compreensão da analogia que se pretende tecer, tem-se que o contraponto (derivado do latim contrapunctum, ou punctuns contra punctus, nota contra nota) é a técnica de combinar linhas musicais, de modo que, ao se acrescentar uma parte a uma outra já existente, a nova parte faz contraponto com a anterior (Sadie, 1994 \& Horta, 1985). "Trata-se de uma relação dupla, em que elementos verticais e horizontais são simultaneamente contrastantes e independentes" (Horta, 1985, p. 87). Além disso, de acordo com Sadie (1994), nas utilizações modernas desse termo, ele não se distingue de polifonia, significando literalmente sons múltiplos. A polifonia (do grego polyphonia) para os gregos antigos era a reunião de vozes ou de instrumentos, que depois passou a carregar o significado de ser uma simultaneidade de várias melodias que se desenvolvem independentemente, mas dentro de uma mesma tonalidade (Ferreira, 1977). Etimologicamente o termo polifonia significa vários sons, vozes múltiplas. É a música em que diversas partes vocais ou instrumentos são combinados contrapontisticamente, soando simultaneamente (Sadie, 1994 \& Horta, 1985).

Retornando agora ao Canon em ré, sabe-se que foi composto para um baixo e três violinos. E de caráter simples e espirituoso. Possui uma sensível simplicidade em termos musicais. Começa com notas longas, que gradualmente se tornam rápidas enquanto o baixo retorna à velocidade inicial.

Isso pode ser afirmado a partir de uma análise musical estrutural. Dentre vários aspectos dessa música, conforme será destacado na sequência, inicialmente percebe-se que formalmente ou estruturalmente ela é de uma simplicidade que causa admiração. De acordo com Candé (1964), a originalidade de Johann Pachelbel reside na pureza e na grandiosa simplicidade do seu estilo, que contrasta com o estilo virtuosístico dos organistas barrocos do norte da Alemanha.

Em termos estruturais, o que existe nessa composição é que ela está na tonalidade de ré maior, apresenta três vozes e um cravo que faz os acordes da progressão harmônica. Uma das vozes é a do baixo, que não participa do efeito cânone, tocando as tônicas. As outras duas vozes são executadas por violinos. Existe uma estrutura básica que se apresenta em oito compassos, acontecendo quinze vezes ao longo da música toda. Dessa forma, ela tem 
120 compassos, mais um fermatado ${ }^{7}$ no final. Seu compasso é quaternário (4/4).

Cada compasso da estrutura básica tem uma função: $1^{\circ}$ - tônica; $2^{\circ}$ - dominante; $3^{\circ}$ - tônica; $4^{\circ}-$ dominante; $5^{\circ}$ - subdominante; $6^{\circ}$ - tônica; $7^{\circ}$ - subdominante; $8^{\circ}$-dominante. Essa progressão harmônica é representada da seguinte forma: I V VIm IIIm IV I IV $\mathrm{V}$, sendo os acordes, nessa tonalidade, respectivamente: | D A Bm F\#m G D G A |. Isso também foi evidenciado na análise harmônica de Summer (1995, p. 36) e na análise musical realizada pelos musicoterapeutas ingleses Wigram, Pedersen e Bonde (2002).

De acordo com a movimentação melódica e harmônica da música, na primeira vez que a estrutura básica é tocada apresentam-se o baixo e o cravo. Na segunda vez, a primeira vOz inicia-se na nota de fá sustenido (fá\#) e vai, em um movimento descendente na escala de ré maior, passando pelos acordes, com os quais cria os seguintes intervalos, em relação à nota tônica destes acordes: $3^{\mathrm{a}} \mathrm{M}, 5^{\mathrm{a}} \mathrm{J}$, $3^{\mathrm{a}} \mathrm{m}, 5^{\mathrm{a}} \mathrm{J}, 3^{\mathrm{a}} \mathrm{M}, 5^{\mathrm{a}} \mathrm{J}, 3^{\mathrm{a}} \mathrm{M}$ e $3^{\mathrm{a}} \mathrm{M}$ (sensível). ${ }^{8} \mathrm{Na}$ terceira vez da estrutura básica, entra a segunda voz fazendo um contraponto, porém, em um movimento paralelo com a primeira voz, com o cânone só se iniciando, efetivamente, na sexta vez em que acontece a estrutura básica. Na quarta e na quinta vez, as vozes passam a se movimentar de modo independente.

Os cânones iniciados na sexta vez que se reapresenta a estrutura básica não são uma simples repetição, ou seja, a voz seguidora não repete a voz líder em um determinado espaço de tempo (compasso) e nos mesmos intervalos única e estritamente. Há um cânone, mas um cânone diferente. Parece que é um cânone levado ao limite, ou seja, à fronteira daquilo que depois não seria mais um cânone, e que só é possível por meio de alguém que domina completamente essa técnica. Pode-se dizer que é um cânone em nível de terceiridade, segundo a compreensão semiótica de Peirce, ${ }^{9}$ em que a máxima resultante lógica e complexa se volta ao simples, ou seja, à primeiridade. As repetições não acontecem de maneira que se possa sentir que algo está repetindo, mas há cânone de ideias melódicas, rítmicas e até de timbres e tessituras (essa última é evidente, mesmo porque são instrumentos musicais pertencentes à mesma família: baixo, violinos e violas).

Análise musical estrutural feita. Leitura da dimensão musical em termos de estrutura apresentada e compreendida. Certo, mas e daí, o que isso tudo implica?

Implica que - e neste momento retoma-se a frase de Ruud (2003) do começo do texto - a música Canon em ré pode se constituir em uma metáfora do processo de construção da identidade, ou constituição do sujeito, como propomos. Ao se compreender o conceito de identidade como identidades contextuais, ou melhor, como identificações em curso, tal como é dito por Sousa Santos (1995), pode-se iniciar a analogia/metáfora da música apresentada com a questão da constituição do sujeito.

Para fazer um resumo da ópera-ou melhor, do cânone - destaca-se que o Canon em ré possui uma construção musical, melódica e rítmica que se inicia em seu baixo contínuo. ${ }^{10}$ Possui, nesse sentido, uma base que é algo que se move na música desde o começo, que tem certa regularidade e, como o próprio nome diz, é contínuo. Está ali, sucessivamente, do início ao fim da sonoridade dessa peça, mas poderia continuar, poderia interromper-se; no entanto, é um fenômeno que de certo modo se sustenta musicalmente falando.

A partir desse baixo contínuo, entra a movimentação musical do cravo, depois uma linha melódica é construída, e segue seu percurso, e ainda uma segunda. Melodias que se entrecruzam; caminham em paralelo; contrapõem-se; geram intervalos entre notas que são diferentes, mas que de certo modo se identificam

\footnotetext{
7 Fermata (palavra de origem italiana): sinal colocado sobre ou sob uma nota ou uma pausa. Indica que a duração do valor dessa nota ou dessa pausa pode ser arbitrariamente prolongada pelo executante. Geralmente, a fermata dobra o valor rítmico escrito (Dicionário Aurélio da Língua Portuguesa, versão digital).

8 Intervalos musicais, a saber: $3^{\mathrm{a}} \mathrm{M}$ (terça maior), $5^{\mathrm{a}} \mathrm{J}$ (quinta justa), $3^{\mathrm{a}} \mathrm{m}$ (terça menor).

9 Terceiridade: "corresponde à camada de inteligibilidade, ou pensamento em signos, por meio da qual representamos e interpretamos o mundo" (Santaella, 1983, p. 51). "Corresponde à nossa esfera cognitiva, ao movimento do pensamento em signos, à captação da estrutura musical, à síntese intelectual por meio da qual representamos e interpretamos o mundo” (Sefekk, 1998, p. 42).

10 "Expressão que se refere à parte ininterrupta de baixo que percorre toda a obra concertante do período barroco (também do Renascimento tardio e do primeiro período clássico) e serve como base para as harmonias” (Sadie, 1994, p. 66).
} 
em alguns momentos e em outros não; são, a priori, independentes, mas que por caminharem juntas - e esse caminhar não significa necessariamente estarem em concordância, mas discordarem também - vão constituindo todo o tecido da peça musical. Afinal, é o movimento da polifonia a simultaneidade de várias melodias que se desenvolvem independentes, dentro de uma mesma tonalidade. Melodias que se identificam na trajetória desse curso, desse percurso, identificações em curso. Melodias que se cruzam, se tecem, acontecem, se contrapõem ou divergem no contexto musical que se iniciou. Algumas melodias vão acontecendo junto a um baixo contínuo e vão configurando aquilo que se escuta no todo dessa música. Um grande e diverso movimento, em que há conversa, diálogo, escolhas que levam a outros lugares, contraposições, contraponto, punctus contra punctus, nota contra nota, enquanto está-se tecendo junto na diversidade sonora. Polifonia. Vários sons. Independentes, mas correndo e ocorrendo juntos em uma trajetória, que depois poderia levar a uma outra sonoridade, se o movimento específico dessa peça continuasse. Contudo, ali ele dura apenas alguns minutos. Um movimento não de repetição, mas de inovação dentro de um já conhecido. Um desconhecido que entra sonoramente e participa junto, permitindo conhecer o que existe e criar algo novo a partir dessa dialogia. Um baixo contínuo que mantém um existente, mas que se inova a cada momento com a presença e co-construção da música, de sons outros que se fazem audíveis e constituem o todo dessa música: um baixo, um cravo, violinos, depois violinos e violas. Uma voz, duas vozes, três vozes que tecem uma síntese. Porque primeiro há uma voz afirmada, depois é negada pela presença e ação de outra, que não a repete integralmente, mas que no embate com a primeira cria outro som, outro todo de sonoridades possíveis graças a isso tudo, e tecem algo completamente novo pelo seu entrecruzamento, algo que só é possível nesse entrecruzamento, nesse, por que não dizer assim, movimento dialético e dialógico (Bakhtin, 2003 \& Faraco, 2006).
Wigram, Pedersen e Bonde (2002, p. 96), ao analisar musicalmente esse cânone, dizem que "la caratteristica che rende più orecchiabile la composizione è che la melodia del canone diventa sempre più vivace e varia mentre l'ostinato resta lo stesso con il suo andamento fisso e stabile". ${ }^{11}$ Essa constatação evidencia também a presença constante de uma dialética entre permanência e mudanças/modificações ao longo do cânone que levam à sua construção, à sua existência musical.

Há elementos que existem, ou vão se constituindo por existirem, e nessa trama toda passam a ser novos e a gerar totalizações novas, uma vez que a eles é dado um novo sentido que surge da relação. Das relações e identificações em curso e que levam a momentos diferentes, enquanto percorrem movimentos diferentes. Isto é, uma síntese de múltiplas identificações em curso e não um conjunto de atributos permanentes (Sousa Santos, 1995), tal como a identidade e o processo de constituição do sujeito.

Por esses aspectos verificamos a possibilidade de tecer uma metáfora com a constituição do sujeito. Eisso, além da significação atribuída, acontece na estrutura dessa música, que busca e constrói algo novo a cada compasso, mas não um novo volátil, ou uma multiplicidade que escapa ou se dilui. Um (re) inovar-se enquanto afirma, nega, cria outra possibilidade e mantém algo de uno também. Existe um uno-permeado de outros, se pensarmos nas relações entre os sons musicais -, existe uma permanência, mas existe uma movimentação, um vir-a-ser que só se constrói no próprio fazer.

Aproximando-se desse viés, Wigram, Pedersen e Bonde (2002, p. 96) colocam a seguinte questão: 'È possibile trovare un'analogia adattabile a questa composizione nella psicologia (evolutiva)? E possibile sperimentare questo canone come una metáfora dei principi di interazione? Noi crediamo che lo sai." ${ }^{12}$

\footnotetext{
11 "A característica que torna mais audível a composição é que a melodia do cânone se torna sempre mais vivaz e varia enquanto o ostinato permanece o mesmo com o seu andamento fixo e estável” (Tradução livre).

12 "É possível encontrar uma analogia adaptável a esta composição na psicologia (evolutiva)? É possível experimentar este cânone como uma metáfora para os/dos princípios de interação? Nós acreditamos que seja” (Tradução livre). Importante ressaltar que os autores chegam a esta constatação, partindo de uma compreensão/visão das músicas sobre um processo de escuta metafórico, em relação às teorias da música como analogia e metáfora (Wigram, Pedersen \& Bonde, 2002, p. 94). Importante ainda salientar que, para responder esta analogia/ metáfora na musicoterapia os autores seguem pelas orientações teóricas psicanalíticas de Winnicott, e da psicóloga evolutiva Margaret Mahler (vide Wigram, Pedersen \& Bonde, 2002, p. 96). A pergunta que se colocam é semelhante à nossa, neste artigo, ou seja, partir da escuta e análise desta música, "Cânone em Ré”, como metáfora/analogia para compreender o processo de constituição do sujeito, obviamente, em nosso caso, orientadas pela epistemologia materialista histórica e dialética na abordagem sócio-histórica da psicologia.
} 
Contradição, embates, movimentos. Um processo inacabado e aberto. Uma síntese inacabada (Maheirie, 2002). Inacabada e aberta porque não se fecha na permanência e aceita outras possibilidades ou movimentos que a ela não apenas se somam, mas que acontecem ora na contradição, ora na unicidade, produzindo sempre um devir, um vir-a-ser. No entanto, como? Se a música termina em um determinado momento. Sim, paára de soar, mas poderia ser tocada de novo e para quem a escuta não seria a mesma, talvez nem mesmo despertaria as mesmas emoções e sentimentos, pois junto a isso quem escuta também não seria mais o mesmo. E, além disso, ao escutá-la uma primeira vez a sensação é que poderia continuar tocando, ou seja, uma necessidade, uma expectativa de que ela não terminaria ali onde o som para de soar e faz-se silêncio, pois seu movimento é tamanho, ou a movimentação que desperta é tanta, que ela faz-se ouvir, faz-se soar, ou segue ressoando enquanto o som, em termos físicos, dá um stop. Talvez porque a questão não é apenas a objetividade, a materialidade, a concretude do fenômeno, mas porque com essa objetividade é tecido um movimento dialético, contínuo, que repercute simultaneamente em construção ou constituição de subjetividade, e que ao mesmo tempo pode ser objetivado em algo que retorna cheinho de presença subjetiva. Movimentos de objetivar, subjetivar, objetivar, subjetivar, objetivar, subjetivar e construir música a partir e com isso tudo - e também constituir sujeitos como uma síntese aberta, inacabada, mutável, em constante movimento.

\section{Constituição do sujeito}

Começamos este novo trecho com uma frase de Sartre, que se configurará em uma nova voz a ser desenvolvida nessa "composição": o projeto "a práxis, com efeito, é uma passagem do objetivo ao objetivo pela interiorização", pela subjetividade (Sartre, 1984, p. 154). Entendendo também, a partir daí, que nenhuma objetividade no mundo humano pode ser desprovida de subjetividade e, ao mesmo tempo, que não há subjetividade que não se objetive.
Com essa ideia é que se pretende, agora, tecer um novo cânone, que tal como no Canon em ré, não irá fazer única e estritamente uma repetição da vOz seguidora sobre a voz líder, mas buscar articular tonalidades, ritmos, progressões harmônicas, intervalos e melodias, aproximando-se da compreensão desse que pode ser o movimento de constituição do sujeito, um movimento, diga-se de passagem, também polifônico.

Para se falar de constituição do sujeito na abordagem sócio-histórica da psicologia, precisa-se, primeiramente, falar do movimento dialético e dialógico que existe entre objetividade e subjetividade, essas duas dimensões que se fazem constituintes do sujeito. Isto é, pela contínua movimentação entre objetividade e subjetividade é que o sujeito vai se constituindo, de modo que esse mesmo sujeito poderia ser definido como produto aberto e inacabado da relação entre subjetividade e objetividade (Maheirie, 2002), em um movimento contínuo e dialético a todo tempo, em que uma está sempre permeada pela outra, uma construção em mão dupla. Um movimento tal como a composição de um cânone - o Canon em ré, por exemplo, em que as vozes ${ }^{13}$ não são uma simples repetição uma da outra, mas um cânone tecido por essas duas vozes e levado ao limite, à fronteira daquilo que depois não mais seria um cânone. ${ }^{14} \mathrm{Ou}$ que até seria, justamente por conter ainda, mas de modo transformado, essas mesmas duas vozes, que também não seriam mais as mesmas, visto que já estariam, por sua vez, transformadas.

Esse movimento dialético e dialógico acontece no espaço e no tempo, em lugares situados, pois sucede que "O sujeito é constituído e constituinte do contexto social no qual está inserido" (Maheirie, 2003, p. 147). Ou ainda: "inserido neste cenário de múltiplas singularidades que se entrecruzam ele [o sujeito $]^{15}$ realiza a sua história e a dos outros, na mesma medida em que é realizado por ela, sendo, por isso, produto e produtor, simultaneamente" (Maheirie, 2002, p. 36). Nesse ponto, a contextualização do espaço, do tempo e do momento histórico se faz imprescindível, uma vez que existem determinações e limites colocados pelo sistema político-social-econômico no qual se

\footnotetext{
13 Aqui se entendam "as vozes” como as dimensões objetiva e a subjetiva do sujeito (nota dos autores).

${ }^{14}$ Assim como Johann Sebastian Bach, que ao trabalhar com o contraponto ao limite permitiu surgir a harmonia, assumindo, então, o contraponto o momento de configurar-se em sistema tonal - já que foi levado ao limite -, da mesma maneira, Pachelbel levando o cânone ao limite poderia, a partir daí, objetivá-lo em outra forma musical.

15 Acrescido pelos autores.
} 
está inserido. E não apenas nesses aspectos, mas na dimensão também cultural, simbólica, ideológica. No entanto, além das determinações, o homem tem a possibilidade de escolha, ou seja, de atuar no mundo (Sartre, 1984). Isso sempre em volta da compreensão de que o sujeito é constituído a partir da objetividade mediada pela subjetividade, e estabelecendo vínculos de relações mais diversas possíveis. Relações em que os outros, com os quais se relaciona, passam a ser mediadores, para o sujeito, de sua própria constituição enquanto singularidade.

Sartre (1984) fala do "projeto" como o motivo pelo qual a realidade humana seja sempre "desejo de ser". De acordo com Maheirie (2002, p. 34), o desejo de ser é "aquilo que movimenta o sujeito no mundo e seu movimento é o impulso ao não existente, aquilo que não se é".

Quando nos projetamos em um desejo de ser, buscamos ser um determinado ser que cristalizamos ao projetá-lo, isto é, projetamos um ser 'cristalizado', de tal forma que o desejo de ser se traduz em desejo de ser em-si ${ }^{16}$. Mas, como este desejo nunca se concretiza, pois a consciência nunca se transforma em em-si, paralelamente o projeto nunca tem como se realizar de fato, nunca havendo a coincidência total e absoluta entre o desejo e o fato, o que faz com que o sujeito nunca se coisifique. Este impulso "em direção a...” torna o sujeito um ser que está sempre além de si mesmo, em um movimento de transcendência constante, que se faz dialético, desde sua origem (Maheirie, 2002, p. 34).

Então o que é esse projeto senão o desejo de ser alguém? O projeto é um sujeito. E junto, de modo intrincado, o seu desejo de ser alguém, se fazer aquele alguém que ele deseja ser. Um alguém, um ser no sentido de essência, e aqui se remete a um sentido antropológico.

O projeto é existencial, projeto da existência de um sujeito. Não é algo que se espera do futuro, em termos de expectativa, muito embora o futuro faça parte desse projeto, assim como o já vivido - o passado e os momentos presentes. É um articular, um existir, um constituir-se sob a trama dessas três dimensões. É o mover-se da subjetividade em relação àquilo que ela não é - ou que ainda não é. A subjetividade enquanto ainda não sendo, enquanto ausência de realidade física, que na dialética com a objetividade e o existente - aquilo que já é - poderá se constituir em realidade física, em objetividade subjetividade objetivada. O processo de constituir-se sujeito passando do objetivo ao objetivo pela subjetividade (Sartre, 1984).

E, no que diz respeito a esse processo, na medida em que se realizam ações, ou seja, na medida em que se objetiva, vai-se cada vez mais materializando esse realizado. $\mathrm{Na}$ medida em que se dá materialidade a esse projeto, se supera e se vai adiante. Desse modo, Sartre (1984) fala que não existe uma coincidência total e absoluta entre o desejo e o fato, porque esse mesmo movimento, ao se realizar e objetivar novas existências, impulsiona para que se vá sempre adiante.

Segundo Maheirie (2002, p. 35),

fazendo-se na pluralidade do contexto, o sujeito, como singularidade humana, está tecido no mundo e caracterizado por uma situação específica. Nela ele se movimenta, se constrói e produz a história, à luz de um projeto. Impulso em direção ao ainda não existente e, simultaneamente, inserido em condições objetivas que a situação lhe impõe, o projeto é a própria práxis vivida no cotidiano.

Essa história, esse projeto, é construída passo a passo no andar cotidiano dos fatos e das relações.

A autora acima citada, ao discutir essas ideias e tecendo uma compreensão a partir de Sartre, diz que:

o projeto define o sujeito, caracterizando a dialética do subjetivo e do objetivo. Como subjetividade objetivada (que se transforma em ato), o projeto é este movimento do sujeito

16 “Os objetos/coisas, como sendo a própria objetividade, Sartre os chamou de ser em-si, ou seja, o ser que é em-si mesmo sua existência, pois não está em 'relação a...' [...]. O para-si é o tipo de ser que é para si mesmo, ou seja, é um tipo de ser que estabelece sentidos, significados para o mundo e também para si mesmo. Esse tipo de ser já se faz, a princípio, negação dialética do em-si” (Maheirie, 2002, p. 33). 
(incluindo seu passado) em direção ao novo, ao inexistente, em um processo de superação que implica recusa e realização, ou seja, transformação e manutenção de uma situação. O homem se define baseado em seu passado, pois este é o que ele é e não pode deixar de ser, mas é em função de um futuro que tal definição acontece, já que é ele quem dá sentido às posições do sujeito (Maheirie, 2002, p. 36).

Transforma e mantém. Transforma porque parte de algo que se mantém e se supera. Mantém porque, ao se transformar, carrega junto os momentos em que já existe para poder se (re)transformar. E isso se pode ver na movimentação musical do Canon em ré, tal como apresentado anteriormente. É com esse olhar que se pode entender, seja no Canon seja na constituição do sujeito, que "segundo a concepção dialética, a passagem do 'ser' ao 'não-ser' não é aniquilamento, destruição ou morte pura e simples, mas movimento para outra realidade. A contradição faz com que o ser suprimido se transforme" (Aranha \& Martins, 1993, p. 89).

Quando começo a esculpir uma estátua, estou diante de uma matéria-prima, a madeira, que depois é negada, isto é, destruída na sua forma natural, mas ao mesmo tempo conservada, pois a madeira continua existindo como matéria, só que modificada, elevada a um objeto qualitativamente diferente, uma forma criada. Portanto, o trabalho nega a natureza, mas não a destrói, antes a recria (Aranha \& Martins, 1993, p. 89).

Aqui se chega a articular diretamente com o movimento de criar e (re)criar: o fazer, a ação, a materialização que o sujeito faz da própria subjetividade, em atividades específicas, tendo resultados concretos deste processo de produção, enquanto também, ao produzir e objetivar produções concretas constrói, constitui, (re)constrói e (re)forma a si mesmo.

De acordo com Zanella (2005, p. 99), "via atividade, o ser humano se apropria da cultura e concomitantemente nela se objetiva, constituindo-se assim como sujeito". A mesma autora pontua que é por meio de sua atividade que o homem pode transformar o contexto social onde vive e onde se insere, movimentando-se em um processo que ao mesmo tempo constitui a história e lhe permite constituir a si e ao seu psiquismo. "A história do desenvolvimento da sociedade e de cada pessoa, portanto, está diretamente relacionada às transformações da atividade humana e dos motivos que a impulsionam" (Zanella, 2005, p. 101).

É preciso verificar, neste ponto, que esse processo, essa movimentação, não se dá pela ação de um sujeito isolado. Ao contrário, é na trama das relações sociais que esse processo ocorre. É a partir do contexto social interpsicológico que os espaços intrapsicológicos tomarão forma e poderão desenvolver as movimentações dialéticas e dialógicas ao longo dos percursos existenciais históricos. Zanella (2005, p. 101) baseia-se no psicólogo russo Lev S. Vygotsky para que se possa visualizar esse processo, ou seja, o processo de constituição do sujeito. Segundo a autora, a dimensão da relação com o outro é uma constante nas explicações de Vygotsky (2000) sobre a constituição do psiquismo humano, em que existe o pressuposto de que esta se origina no contexto das relações sociais. Para Vygotsky, a natureza psíquica do homem vem a ser o conjunto de relações sociais transladadas ao interior e convertidas em funções da personalidade e em formas de sua estrutura (Vygotsky, 1929/2000).

Isto é, compreende-se aqui o sujeito como um ser que se constitui, dialética e dialogicamente, por meio das relações que vivencia no mundo, produzindo sua história ao mesmo tempo em que produz a dos outros e é por eles produzido. Constitui-se, portanto, a partir de determinações econômicas, sociais e culturais, orientado por um futuro, mediado semioticamente no contexto específico no qual se encontra.

Essa mediação semiótica se dá principalmente por meio da ação do signo linguístico - nas suas mais variadas formas - e das funções da linguagem - segundo compreendido em Vygotsky (1929/2000, 1992) e Bakhtin (2006) - ao serem utilizados pelos sujeitos em relação. Isso configura a natureza social e cultural das funções psíquicas superiores, permitindo ao sujeito produzir significações em suas ações e vivências concretas no cotidiano e uma dimensão simbólica da vida (Pino, 2005).

Todas essas reflexões demonstram, mais uma vez remetendo-se ao Canon em ré, que sem a relação entre as vozes aquelas vozes que constituem a polifonia - ou sem a relação entre as linhas rítmicas e melódicas do baixo, do próprio cravo e a polifonia tecida entre violinos e violas - o cânone não poderia existir. Uma voz precisa da outra para existir, e indo um pouco 
mais adiante, ou mais a fundo, cada nota musical em si é afirmada e se integra aos movimentos melódicos e harmônicos graças às outras notas, as demais notas musicais, que junto ou contrariamente a ela tecem o próprio fato do existir enquanto nota, enquanto som, integrando, no contexto total da composição, a forma do cânone, que depois se especificou, ou por que não dizer se constituiu, no Canon em ré, pela atividade e pelo significado que atribuiu, pela objetivação musical de Johann Pachelbel, que, por sua vez, enquanto sujeito, músico, organista, professor, compositor, teve também a sua própria história, inserido num determinado contexto histórico-social e cultural, também musical, o período Barroco da música europeia ocidental, que o constituiu enquanto tal e objetivou, nesse contexto todo, suas atividades musicais.

Cada pessoa, para Vygotsky (2000, p. 33),

é 'um agregado de relações sociais encarnadas num indivíduo', donde se depreende que só há sujeito porque constituído em contextos sociais, os quais, por sua vez, resultam da ação concreta de seres humanos que coletivamente organizam o seu próprio viver (Zanella, 2005, p. 102).

Daí se compreende que o singular sustenta e embasa o coletivo e que todo o coletivo está presente no singular. Essa dinâmica também existe e é vista na relação entre as notas musicais. Faz-se ouvir o que diz Queiroz (2003), que se fundamenta na visão filosófica e psicológica da música do filósofo Victor Zuckerkandl. Nessa visão, as notas musicais estabelecem de imediato uma relação entre elas mesmas, e se relacionam dentro da ordem do sistema que as cria. Diz Zuckerkandll (1976, p. 95):

as notas musicais existem tão antes da música como os números antes da matemática: um nasceu com o outro. Em um certo sentido pode-se igualmente dizer que as notas foram criadas pela música: "É a música que dá nascimento às notas" [...]. Foi o impulso para criar a música que criou as notas. Não há notas ao acaso, então, subseqüentemente colocadas em ordem ou arranjadas em um sistema; as notas musicais são uma ordem e não têm existência exceto dentro de um sistema.

As notas musicais não têm existência a não ser dentro de um sistema que as relaciona e em que elas mesmas se relacionam umas com as outras. Para Queiroz (2003), o que faz de uma nota um evento musical é ela conter em si todo um sistema de notas. O autor tece uma analogia com a matemática a título de ilustração: "a comparação com os números na matemática deverá ser suficientemente clara. Não poderia existir o número 3 , não existisse todo o sistema de números; não fosse todo o sistema de números, o 3 não teria sentido como tal" (Queiroz, 2003 , p. 52). A nota pressupõe o sistema de notas, as relações entre as notas, ao passo que esse mesmo sistema, para existir, necessita da presença singular de cada nota. Notas entrelaçadas, entrecruzadas, que pela (re)criação humana constituem música(s).

As notas relacionam-se entre si e tornam-se ativas, isto é, apresentam-se como forças dinâmicas, em que ora a sensação de equilíbrio de uma determinada nota é perturbada, ora há um relaxamento da tensão. Todas essas qualidades são percebidas diretamente pela audição quando soam mais de uma nota. As notas interagem segundo forças de atração, de repulsão, de tensão, de relaxamento, de esforçar-se em direção a, de equilibrar-se em si mesma. Estas são chamadas de qualidades dinâmicas por Zuckerkandl. São qualidades das notas que lhe dão uma dinâmica particular dentro da ordem da qual fazem parte. São qualidades que não estão presentes em uma nota única, propriamente, pois não existe uma nota separada do sistema das notas (uma escala ou tonalidade, por exemplo) - um osciloscópio não registra esta qualidade da nota, pois esta não é uma qualidade física, não está na onda vibratória que caracteriza a nota. A qualidade dinâmica da nota musical existe porque ela faz parte de uma ordem, fora da qual perde seu significado, apesar de conservar suas características físicoacústicas e ondulatórias (Queiroz, 2003, p. 54).

E, dessa forma, as notas musicais podem constituir sentidos ao estarem entrelaçadas na trama maior de mais notas que se relacionam formando a melodia, a harmonia. As qualidades dinâmicas que emergem a partir do enredar-se das notas musicais é o que permite à melodia ser algo mais, algo além de uma simples sucessão de notas, e também o que permite à música ser algo além de apenas fenômeno acústico. Segundo Queiroz (2003,p. 55), "a qualidade 
dinâmica é a qualidade propriamente musical das notas". Propriamente no sentido de que pode singularizar aquilo que poderia ser um ponto essencial no motivo de existir das notas musicais, e que as constitui enquanto tais: a qualidade de estarem dinamicamente em relação. Tal qual o(s) sujeito(s). Segundo Maheirie (2002, p. 39), "O sujeito, ou a identidade, são construídos por oposições, conflitos e negociações, sendo constantemente inventada por estes sujeitos, em um processo aberto, nunca acabado".

\section{Consideraçóes finais}

A ideia é ir e vir, ou seja, olhar como acontece-ou pode acontecer-o processo de constituição do sujeito, e olhar, ou seja, ouvir como se passa esse movimento na música também, já que se escolheu uma composição musical para tecer um dueto com a compreensão do processo de constituição do sujeito. Um dueto com as vozes da psicologia sócio-histórica em uma interface com a música, que aqui se entrelaçam com a ideia proposta pelo Canon em ré, em que as vozes não se repetem ou não se imitam ipsis litteris, mas inauguram um movimento de um cânone tal levado ao limite, à fronteira daquilo que depois não seria mais um cânone. Então, num movimento aberto e inacabado, essas vozes vão tecendo uma síntese também aberta e inacabada, que agora, neste momento, desemboca na coda. ${ }^{17}$

A coda por si só já traz aideia de movimento dialético, de finalizar sem concluir, parafraseando Maheirie (2001). Ou seja, encerrando esse dueto com aquilo que se pode chamar de coda, faz-se ouvir a voz de Zanella (2005), em que "[...] o encontro permanente e incessante com um outro possibilita reconhecer a pluralidade do que se é e do que se pode vir a ser" (Zanella, 2005, p. 15). Essa voz contrasta e tece também um cânone com outra voz, de Maheirie (2002), quando diz que "constituir-se como sujeito é, nesta perspectiva, realizar a dialética do objetivo e do subjetivo, já que o sujeito existe como subjetividade objetivada, que pela subjetividade (negação), se objetiva novamente, encontrando, por meio da subjetividade (negação), uma nova objetivação e assim infinitamente" (Maheirie, 2002, p. 37).

\section{"A existência é o lançar-se contínuo às possibilida- des sempre renovadas".}

(Sartre, 1984, p. 304)

\section{Referências}

Andrade, J. (Org.). (2005). Música. Camerata Antiqua de Curitiba. Coro e orquestra. Curitiba: ICAC.

Aranha, M. L. de A., Martins, M. H. P. (1993). Filosofando: Introdução à filosofia (2a ed.). São Paulo: Moderna.

Bakhtin, M. (2003). Estética da criação verbal (4a ed.). São Paulo: Martins Fontes.

Bakhtin, M. (Volochínov). (2006). Marxismo e filosofia da linguagem (12a ed.). São Paulo: Hucitec.

Candé, R. de. (1964). Dicionário dos músicos. Lisboa: Edições 70.

Faraco, C. A. (2006). Linguagem \& diálogo: As idéias lingüísticas do círculo de Bakhtin. Curitiba: CriarEdições.

Ferreira, A. B. de H. (1977). Dicionário Aurélio da Língua Portuguesa. Rio de Janeiro: Nova Fronteira.

Franco, A. T. (2005). O adágio de Albinoni e o Canon de Pachelbel. Recuperado em 11 jul.2005, em http:// www.polors.adagio.htm

Horta, L. P. (Ed.). (1985). Dicionário de música Zahar. Rio de Janeiro: Zahar.

Maheirie, K. (2001). Sete mares numailha: Amediação do trabalho acústico na construção de identidade coletiva. São Paulo, Tese de Doutorado, Pontifícia Universidade Católica de São Paulo, São Paulo.

Maheirie, K. (2002). Constituição do sujeito, subjetividade e identidade. Interações, 8(13), 31-44.

Maheirie, K. (2003). Processo de criação no fazer musical: uma objetivação da subjetividade, a partir dos trabalhos de Sartre e Vygotsky. Psicologia em Estudo, 8(2), 147-153.

${ }^{17}$ Coda: palavra italiana que designa cauda. É o trecho de encerramento de uma obra musical, baseado na repetição de parte de um tema principal, ou uma melodia independente. "Parte final de um movimento, cujo propósito é servir de remate à peça. Em um movimento na forma sonata, por exemplo, segue-se à recapitulação e proporciona uma sensação conclusiva. Embora seja a palavra italiana que significa 'cauda', é considerada uma parte da estrutura musical, mais que um apêndice” (Horta, 1985, p. 82). 
Pino, A. (2005). As marcas do humano: Às origens da constituição cultural da criança na perspectiva de Lev S. Vygotski. São Paulo: Cortez.

Queiroz, G. J. P. de. (2003). Aspectos da musicalidade e da música de Paul Nordoff e suas implicações na prática clínica musicoterapêutica. São Paulo: Apontamentos.

Ruud, E. (2003). Curso "Musicologia, Cultura e Musicoterapia - Música e Identidade". Rio de Janeiro, Conservatório Brasileiro de Música - Centro Universitário (Informação verbal de curso), 03 a 05 de novembro.

Sadie, S. (Ed.). (1994). Dicionário Grove de Música. Rio de Janeiro: Zahar.

Santaella, L. (1983). O que é semiótica. São Paulo: Brasiliense.

Sartre, J-P. (1984). Questão de método. São Paulo: Abril Cultural.

Sekeff, M. de L. (1998). Música e semiótica. In L. Tomás (Org.). De sons e signos: Música, mídia e contemporaneidade (pp. 33-58). São Paulo: EDUC.

Souza Santos, B. de. (1995). Pela mão de Alice: O social e o político na pós-modernidade. (3a ed.). São Paulo: Cortez.

Summer, L. (1995). Melding musical and psychological processes: The therapeutic musical space. Journal of the Association for Music and Imagery, 4, 37-48.

Vygotsky, L. S. (2000). Manuscrito de 1929. Educação \& Sociedade, 71, 21-45 (Originalmente publicado em 1929).

Wigram, T., Pedersen, I. N., Bonde, L. O. (2002). Guida generale alla musicoterapia. Teoria, pratica clinica, ricerca e formazione. Roma: Ismez Editore.

Zanella, A. V. (2005). Sujeito e alteridade: Reflexões a partir da psicologia histórico-cultural. Psicologia \& Sociedade, 17(2), 99-104.

Zuckerkandll, V. (1976). Man the musician. Princeton: Princeton University Press.

Recebido: 15/12/2008

Received: 12/15/2008

Aprovado: 04/05/2009

Approved: 05/04/2009 